\title{
CDISC SDTM Intervention Type Terminology
}

National Cancer Institute

\section{Source}

National Cancer Institute. CDISC SDTM Intervention Type Terminology. NCI Thesaurus.

Code C99078.

Terminology associated with the intervention type codelist of the Clinical Data

Interchange Standards Consortium (CDISC) Study Data T abulation Model (SDT M). 